\title{
Numerical investigation of fresh water - suspended sediment mixtures discharging into saline ambient water
}

\author{
A. Georgoulas, P. Angelidis \& N. Kotsovinos \\ Democritus University of Thrace, Xanthi, Greece
}

T. Panagiotidis

Institute of Technology, Kavala, Greece

\begin{abstract}
In this paper, hypopycnal and hyperpycnal particulate currents that are formed at river outflows in the sea are studied. The main aim is the use of CFD methods, in order to investigate the plunging mechanism in the case of hyperpycnal currents. Two series of numerical experiments are conducted. The first series, aims to validate the numerical model by checking its ability in capturing the critical suspended sediment concentration for plunging. The second series, aims to investigate the dependence of the plunge depth from the initial flow conditions, in the case of hyperpycnal currents. From the analysis of the results, an empirical equation is derived which relates the plunge depth with the initial conditions. It is also found that secondary hyperpycnal currents, can be generated indirectly, from hypopycnal currents, due to descending sediment fingers. The model predictions, in the present paper are in agreement with previous investigations.
\end{abstract}

\section{INTRODUCTION}

When a sediment laden river enters the relatively quiescent sea water or the water of a lake or reservoir, it meets waters of slightly different density, due to the corresponding differences in temperature, salinity or suspended sediment concentration. According to the magnitude of these density differences two extreme particulate currents can be formed. First, if the density of the fresh water-suspended sediment mixture of the river is lower than that of the receiving quiescent water body, a hypopycnal particulate current will be formed that will continue to flow along the free water surface, as an overflow. Second, when the density of the river is higher than the density of water in the receiving basin, at some distance from the river mouth, the river plunges to the bottom of the receiving basin, forming a hyperpycnal particulate current that continues to flow as an underflow, along the bottom boundary of the basin (Mulder \& Alexander 2001).

According to the literature, for a direct conversion of a sediment laden river outflow to a hyperpycnal turbidity current in seawater, the critical concentration of suspended sediment required is 36 to $43 \mathrm{~kg} / \mathrm{m}^{3}$ (Mulder et al. 2003). In cases that the suspended sediment concentration of a river entering the sea is below this critical value, a hypopycnal current is formed. The investigation of the plunging of a river discharging into the sea or into a lake or reservoir is of great importance and has been previously studied by various researchers in the laboratory (Lee \& Yu 1997, Kostic \& Parker 2003b, Parsons et al. 2001), as well as with the application of numerical models (Kassem \& Imran 2001, Kostic \& Parker 2003a, Dallimore et al. 2004). Most of these works are limited in the investigation of plunging underflows into lakes and reservoirs.

The main aim of the present paper is the use of Computational Fluid Dynamics (CFD) methods that are offered by the commercial software FLUENT, for the numerical simulation of the plunging phenomenon associated with the discharge of fresh water - suspended sediment mixtures into saline ambient water. More specifically, a 3D numerical model is applied at a laboratory scale configuration, in order to investigate the variation of the plunge depth with respect to the initial flow conditions, simulating a range of hyperpycnal flows with different initial densimetric Froude numbers. The numerical model used in the simulations, is tested against pub- 
lished laboratory experiments on hyperpycnal particulate currents, in the work of Georgoulas et al. (2009). Finally, an additional series of numerical runs are conducted in order to further validate the numerical model, by checking its ability in capturing the critical suspended sediment concentration for the transition from hypopycnal to hyperpycnal particulate currents.

\section{DESCRIPTION OF NUMERICAL MODEL}

The numerical model used in the present paper, solves the modified Reynolds-averaged NavierStokes equations, applied to each phase in the flow. The modifications involve the introduction of the volume fractions for the various phases, and mechanisms for the exchange of momentum between the phases. Closure of the turbulence stress terms is achieved by application of the RNG k- $\varepsilon$ model. The governing equations are solved sequentially using the control volume method. The equations and the solution procedure are presented and discussed in detail, in the work Georgoulas et al. (2009). Therefore, due to space limitations, these equations are not presented here.

\section{DESCRIPTION OF NUMERICAL SIMULATIONS}

The geometry and the general conditions of the physical problem that is investigated numerically in the present paper are depicted in Figure 1.

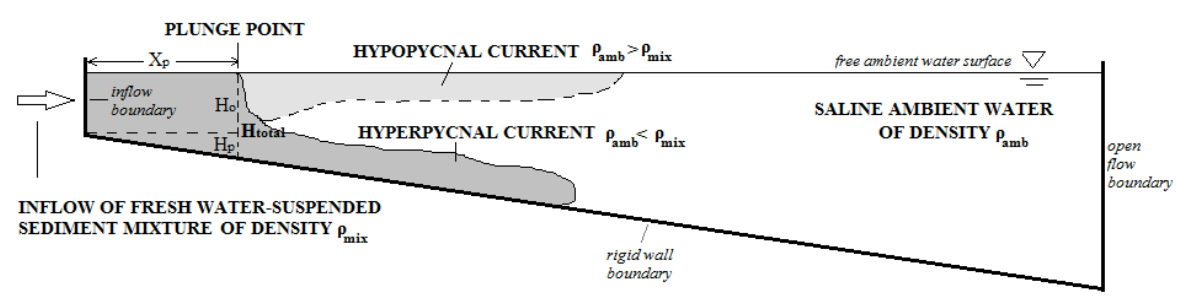

Figure 1. Geometry and general conditions of the physical problem under investigation $(\mathrm{Ho}=$ inflow depth; $\mathrm{Hp}=$ Htotal-Ho $=$ plunge depth; $\mathrm{Xp}=$ plunge distance) .

As it can be seen, the physical problem under numerical investigation is the study of the inflow of fresh water-suspended sediment mixtures discharging into a laboratory scale tank, which is initially filled with saline water. This configuration serves as an experimental analog to natural sediment-laden rivers discharging into the sea. The flows examined in the present paper are treated numerically as multiphase flows, with saline ambient water being the primary phase and fresh water and suspended sediment particles being the secondary phases. The granular phase (suspended sediment) consists of very fine sand particles of diameter $d_{\text {sediment }}=69 \mu \mathrm{m}$.

The numerical geometry, computational mesh and the boundary conditions that numerically represent the physical problem studied in the present paper are illustrated in Figure 2. The computational domain is $8 \mathrm{~m}$ long, $4 \mathrm{~m}$ wide, with a minimum depth of $0.5 \mathrm{~m}$ at its upstream end and a maximum depth of $1.7 \mathrm{~m}$ at its downstream end. Its upstream vertical boundary consists of two solid walls with dimensions $1.9 \times 0.5 \mathrm{~m}^{2}$, and a small opening at the middle with dimensions $0.2 \times 0.5 \mathrm{~m}^{2}$, representing the inflow boundary (inlet). The bottom inclined boundary consists of a solid wall, while the horizontal boundary at the top of the computational domain represents the free surface of the saline ambient water. Finally, the left, right and downstream vertical boundaries of the domain represent open flow boundaries (outlets).

For the inflow a "velocity inlet" boundary condition is applied. For the solid boundaries of the domain, a "wall" boundary condition is applied with a no-slip shear condition. Moreover, "standard wall functions" are applied, for the prediction of the turbulent quantities at the near wall regions. 


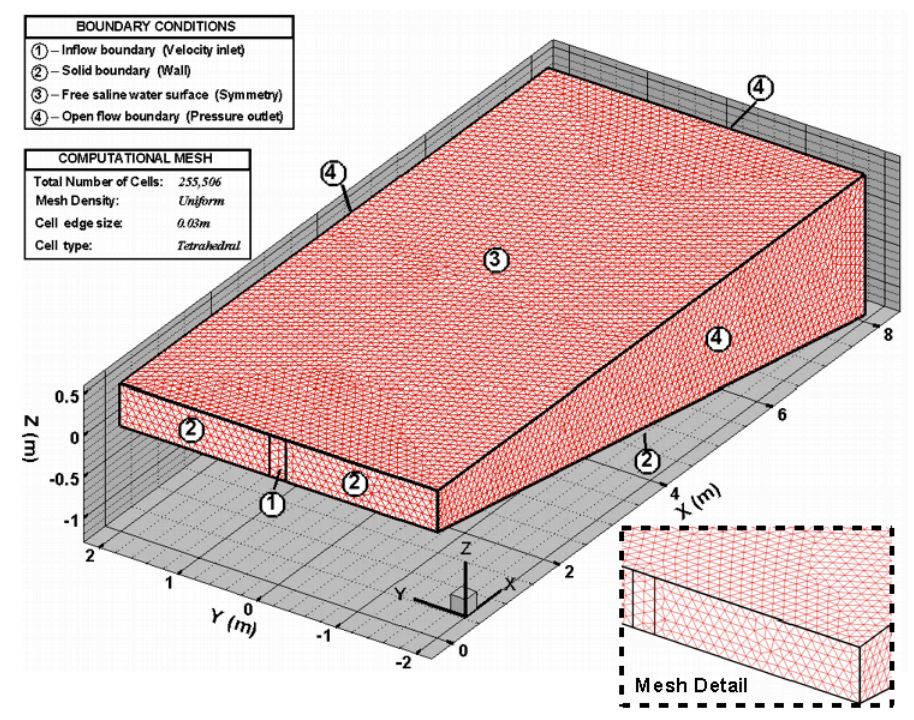

Figure 2. Numerical geometry, computational mesh and boundary conditions.

For the open flow boundaries a "pressure outlet" boundary condition is applied. Using this type of boundary condition, all flow quantities at the outlets are extrapolated from the flow in the interior domain. A set of "backflow" conditions can be also specified, allowing reverse direction flow at outlets during the solution process. In other words, this type of outlet condition serves as an open flow boundary, allowing the flow to freely exit or enter the computational domain during the calculations. Finally, for the free water surface of the ambient saline water a "symmetry" boundary condition is used. Thus, there are neither convective nor diffusive fluxes across the top surface. This approximation of free surface has also been used successively by other researchers in literature (Farrel \& Stefan 1986, Imran et al. 2004, Huang et al. 2005). A mesh consisting of 255,506 tetrahedral computational cells, uniformly distributed in the solution domain, was used for the simulations presented in the present paper.

In order to see if the proposed numerical model successfully predicts the critical suspended sediment concentration for the transition from hypopycnal to hyperpycnal turbidity currents, a first series of runs with varying suspended sediment concentrations were conducted prior to the runs associated with the main investigation aim of the present paper. In order to investigate the variation of the plunge depth $\left(\mathrm{H}_{\mathrm{p}}\right)$, with respect to the flow initial conditions of hyperpycnal particulate currents, a second series of runs (numerical experiments) with varying suspended sediment concentrations and inflow velocities were simulated. For all of the runs (first and second series), $\rho_{\text {ambient water }}=1028.75 \mathrm{~kg} / \mathrm{m}^{3}, \rho_{\text {inflow water }}=999.099 \mathrm{~kg} / \mathrm{m}^{3}, \rho_{\text {sediment }}=2650 \mathrm{~kg} / \mathrm{m}^{3}$. The initial conditions of first and second series of numerical runs are summarized in Table 1.

Table1. Initial conditions for the first and second series of numerical runs

\begin{tabular}{|l|l|l|l|l|l|l|l|l|}
\hline \multicolumn{7}{|l|}{ TABLE 1} \\
\hline Run & \multicolumn{2}{l|}{$\begin{array}{l}\text { Initial conditions for first series of numerical } \\
\text { runs }\end{array}$} \\
& $\mathrm{C}_{\text {sediment }}$ & $\mathrm{U}_{\text {inflow }}$ & $\mathrm{Re}$ & $\mathrm{Fr}_{0}$ & $\mathrm{C}_{\text {sediment }}$ & $\mathrm{U}_{\text {inflow }}$ & $\mathrm{Re}$ & $\mathrm{Fr}_{0}$ \\
\hline & Vol.\% & $\mathrm{m} / \mathrm{sec}$ & & & Vol.\% & $\mathrm{m} / \mathrm{sec}$ & & \\
\hline 1 & 0.1 & 0.05 & $2.27 \times 10^{4}$ & 0.14 & 10 & 0.05 & $2.27 \times 10^{4}$ & 0.06 \\
\hline 2 & 0.5 & 0.05 & $2.27 \times 10^{4}$ & 0.16 & 3 & 0.05 & $2.27 \times 10^{4}$ & 0.16 \\
\hline 3 & 1.0 & 0.05 & $2.27 \times 10^{4}$ & 0.20 & 4 & 0.05 & $2.27 \times 10^{4}$ & 0.12 \\
\hline 4 & 1.5 & 0.05 & $2.27 \times 10^{4}$ & 0.33 & 2 & 0.05 & $2.27 \times 10^{4}$ & 0.39 \\
\hline 5 & 2.0 & 0.05 & $2.27 \times 10^{4}$ & 0.39 & 2 & 0.1 & $4.54 \times 10^{4}$ & 0.79 \\
\hline 6 & 2.5 & 0.05 & $2.27 \times 10^{4}$ & 0.21 & 2 & 0.15 & $6.81 \times 10^{4}$ & 1.18 \\
\hline 7 & 3.0 & 0.05 & $2.27 \times 10^{4}$ & 0.16 & 2 & 0.2 & $9.08 \times 10^{4}$ & 1.57 \\
\hline 8 & 3.5 & 0.05 & $2.27 \times 10^{4}$ & 0.14 & 2 & 0.25 & $11.35 \times 10^{4}$ & 1.97 \\
\hline 9 & 4.0 & 0.05 & $2.27 \times 10^{4}$ & 0.12 & 2 & 0.3 & $13.62 \times 10^{4}$ & 2.37 \\
\hline 10 & 10 & 0.05 & $2.27 \times 10^{4}$ & 0.06 & 2 & 0.40 & $18.16 \times 10^{4}$ & 3.16 \\
\hline 11 & & & & & 2 & 0.60 & $27.24 \times 10^{4}$ & 4.74 \\
\hline
\end{tabular}




\section{RESULTS AND DISCUSSION}

Figure 3 below, displays the spatial evolution of the generated particulate currents for each of the first series of runs summarized in Table 1 , at time $t=100 \mathrm{sec}$ from the initiation of the mixture inflow into the tank. As it can be observed, for runs 1 and 2 a hypopycnal particulate current is formed evolving along the free surface of the ambient saline water. In run 3 , the generated current consists of two distinct parts. The first part is a hypopycnal current that evolves along the free surface, while the second part is a hyperpycnal current that evolves along the bottom boundary. At this point it should be mentioned that the hyperpycnal part of the generated particulate current, is formed at a later stage than the hypopycnal part. Therefore, in the case of run 3 the overall particulate current can be considered to be mainly hypopycnal. In run 4 a different mechanism is observed. After the beginning of the simulation the fresh water - suspended sediment mixture enters the tank uniformly covering the entire depth of the tank. As the evolution of the mixture continues, the bottom part of the generated current accelerates while the top part decelerates and finally a hyperpycnal current that continuous to flow along the bottom boundary of the tank, is formed. Finally, in runs 5-10, the fresh water - suspended sediment mixtures, plunge almost directly to the bottom boundary of the tank, forming hyperpycnal particulate currents.

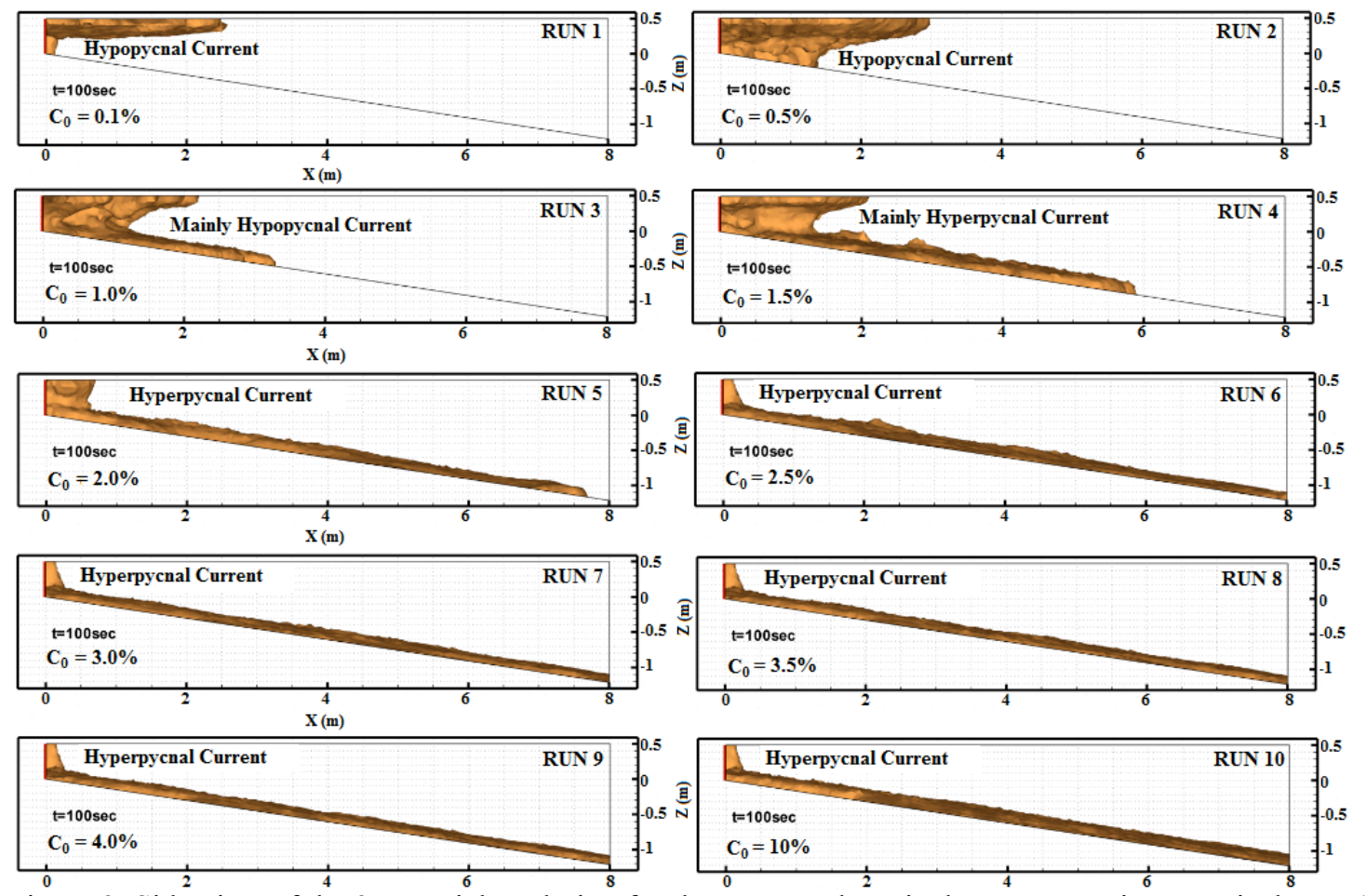

Figure 3. Side view of the 3D spatial evolution for the generated particulate currents, in numerical runs 110 , at $\mathrm{t}=100 \mathrm{sec}$ (first series of runs).

From the above observations, it is evident that the critical initial suspended sediment concentration value, for the transition from the hypopycnal to the hyperpycnal state, is the one used in numerical run $4, \mathrm{C}_{\mathrm{sed}, \mathrm{cr}}=1.5 \%$ (by volume), which yields a suspended sediment mass concentration of $39.75 \mathrm{~kg} / \mathrm{m}^{3}$. This value falls between the range of critical values reported in the literature $\left(36-43 \mathrm{~kg} / \mathrm{m}^{3}\right)$ and therefore it can be concluded that the numerical model used in the present paper, successfully captures the transition from the hypopycnal to the hyperpycnal state, in the case of particulate currents that are formed during the inflow of fresh-water suspended sediment mixtures into saline ambient water.

Another important observation is that the hyperpycnal part of the particulate current that is formed in numerical run 3, is generated due to downward (descending) sediment fluxes that detach from the base of the surface evolving, hypopycnal part. In fact this observation is also evident for the rest hypopycnal cases (runs 1 and 2), but it occurs at times greater than 100 sec. This observation is indicated with more detail in Figure 4, where the spatial evolution of the 
generated particulate current is illustrated with respect to time, in front and side views, indicatively, for the case of numerical run 3 . As it can be observed at time $t=20 \mathrm{sec}$, a hypopycnal current has already been formed, that spreads out radically in all directions, along the free surface of the saline ambient water. At $\mathrm{t}=40 \mathrm{sec}$, descending sediment fluxes (sediment fingers) that have been detached from the base of the initially generated hypopycnal current, have just reached the bottom boundary of the tank. At $\mathrm{t}=60 \mathrm{sec}$, a hyperpycnal current has already been formed that spreads radically in all directions along the bottom boundary. From this time and on, the hyperpycnal current is continuously fed by successive sediment fingers, that descent from the surface evolving hypopycnal current. This is clearly shown for time $t=160 \mathrm{sec}$. This finding, is in agreement with the work of Parsons et al. 2001.

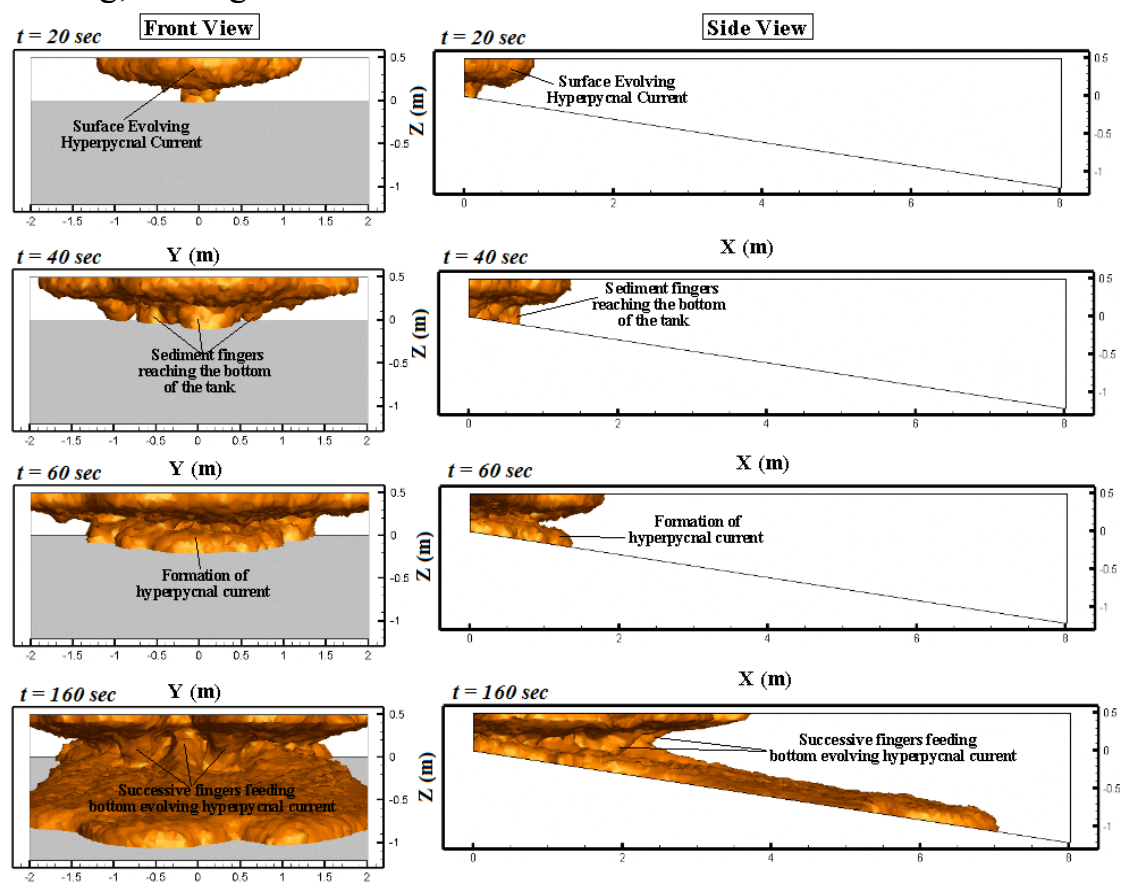

Figure 4. Spatial and temporal evolution of particulate current generated in run 3 (front and side views).

The variation of the plunge depth with respect to the initial conditions for the second series of runs is depicted in Figure 5, where the plunge depth $\left(\mathrm{H}_{\mathrm{p}}\right)$ is plotted against $\left(\mathrm{q}_{\mathrm{o}}{ }^{2} / \mathrm{g}^{\prime}\right)^{1 / 3}(\mathrm{~m})$. Where $\mathrm{q}_{\mathrm{o}}=$ mixture inflow discharge per unit width; $\mathrm{g}^{\prime}=\mathrm{g}\left(\rho_{\mathrm{m}^{-}} \rho_{\mathrm{a}}\right) / \rho_{\mathrm{a}}=$ reduced gravity; and $\mathrm{g}=$ gravitational acceleration; $\rho_{\mathrm{m}}=$ density of fresh water - suspended sediment mixture; and $\rho_{\mathrm{a}}=$ ambient saline water density. As it can be seen the numerical model predictions compare well with the corresponding predictions of the empirical relationships proposed by Sign \& Shah (1971) and Savage \& Brimberg (1975). It is also obvious from the predictions of the present study that the variation of plunge depth with respect to the initial conditions follows a second order polynomial relationship.

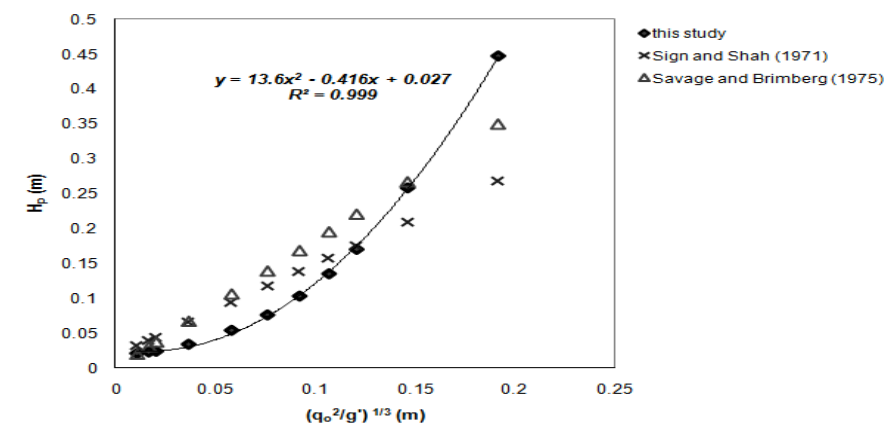

Figure 5. Variation of plunge depth with inflow conditions. 


\section{CONCLUSIONS}

At the present paper, a 3D numerical model is used, for the simulation the plunging phenomena associated with fresh water - suspended sediment mixtures, discharging into saline ambient water. Two series of numerical experiments are conducted. The first series, aims to further validate the numerical model by checking its ability in capturing the critical suspended sediment concentration for plunging. The second series, aims to investigate the variation of the plunge depth with respect to the initial flow conditions (inflow conditions), in the case of hyperpycnal currents. The simulation results indicate, that the numerical model used in the present paper successfully predicts the critical concentration value, for the transformation of a sediment laden inflow into a hyperpycnal current. Another important conclusion that can be withdrawn from the first series of numerical runs is that secondary hyperpycnal currents can also be generated at river outflows with suspended sediment concentrations, much lower that the critical value required for rendering the sediment laden river water, heavier than the saline ambient water of the sea. From the second series of numerical runs of the present paper, it is concluded that the variation of the plunge depth with respect to the inflow conditions is best described by a second order polynomial relationship. It should also be mentioned that the overall results presented in the present paper, are in good agreement with previous experimental, numerical and field investigations. Therefore, as a general conclusion, the overall numerical approached that is used in the present paper, can serve as an attractive tool for the investigation of particulate density currents that are generated at river outflows in the sea, lakes and reservoirs.

\section{REFERENCES}

Bournet, P.E., Dartus, D., Tassin, B. \& Vinçon-Leite 1999. Numerical Investigation of Plunging Density Current. Journal of Hydraulic Research 125 (6): 584-894.

Dallimore, C.J., Imberger, J. \& Hodges, B.R. 2004. Modeling a Plunging Underflow. Journal of Hydraulic Engineering 130 (11): 1068-1076.

Farrell, G.J. \& Stefan, H.G. 1986. Buoyancy induced plunging flows into reservoirs and coastal regions. Tech.Rep. No.241, At. Anthony Falls Hydr. Lab., Univ. of Minnesota, Minneapolis.

Georgoulas, N.A., Angelidis, B.P., Panagiotidis, G.T. \& Kotsovinos E.N. 2009. 3D numerical modelling of turbidity currents. Revised manuscript, resubmited for publication.

Huang, H., Imran, J. \& Pirmez, C. 2005. Numerical model of turbidity currents with a deforming bottom boundary. Journal of Hydraulic Engineering 131(4):283-293.

Imran, J., Kassem, A. \& Khan, S.M. 2004. Three-dimensional modeling of density current. I. Flow in straight confined and unconfined channels. Journal of Hydraulic Research 42(6):578-590.

Kassem, A. \& Imran, J. 2001. Simulation of turbid underflows generated by the plunging of a river. Geology 29 (7): 655-658.

Kostic, C. \& Parker, G. 2003a. Progradational sand-mud deltas in lakes and reservoirs. Part 1. Theory and numerical modeling. Journal of Hydraulic Research 41 (2): 127-140.

Kostic, C. \& Parker, G. 2003b. Progradational sand-mud deltas in lakes and reservoirs. Part 2. Experiment and numerical simulation. Journal of Hydraulic Research 41 (2): 141-152.

Lee, H.Y. \& Yu, W.S. 1997. Experimental study of reservoir turbidity current. Journal of Hydraulic Engineering 123 (6): 520-528.

Mulder, T. \& Alexander, J. 2001. The physical character of subaqueous sedimentary density flows and their deposits. Sedimentology 48: 269-299.

Mulder, T., Syvitski, J.P.M., Migeon, S., Faugeres, J.C. \& Savoye, B. 2003. Marine hyperpycnal flows: initiation, behavior and related deposits. A review. Marine and Petroleum Geology 20: 861-882.

Parsons, J.D., Bush, J.W.M. \& Syvitski J.P.M. 2001. Hyperpycnal plume formation from riverine outflows with small sediment concentrations. Sedimentology 48: 465-478.

Savage, S. B. \& Brimberg, J. 1975. Analysis of plunging phenomena in water resources. Journal of Hydraulic Research. 13(2): 187-204.

Singh, B. \& Shah, C.R. 1971. "Plunging phenomenon of density currents in reservoirs." Houille Blanche, 26(1), 59-64. 